\title{
Translanguaging as a Culturally Sustaining Pedagogical Approach: Bi/Multilingual Educators' Perspectives
}

\author{
Roula Tsokalidou and Eleni Skourtou
}

\begin{abstract}
In this paper we will focus on data from bi/multilingual educators and discuss aspects of translanguaging as a Culturally Sustaining Pedagogy (Paris and Alim, Culturally Sustaining Pedagogies. Teaching and Learning for Justice in a Changing World, Teachers College Press, New York, 2017). The data from the bi/multilingual educators come from a recent qualitative research (Tsoka-

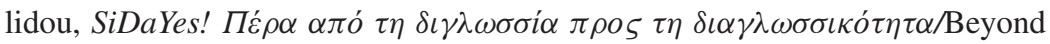
bilingualism to translanguaging, Gutenberg, Athens, 2017) that aimed to bring forward the issue of translanguaging (TL) in the everyday life of multi/bilinguals. Our findings suggest that TL could function as a means of increasing the confidence and self-esteem of minoritized students, while offering them a feeling of normality and pride for their linguistic and cultural backgrounds. It also becomes clear from our data that going against the grain of monolingualism and mono-culturalism is a great challenge for all.
\end{abstract}

\section{Keywords}

Translanguaging $\cdot$ Culturally sustaining pedagogy $\cdot$ Multilingual educators

\author{
R. Tsokalidou $(\bowtie)$ \\ Aristotle University of Thessaloniki, Thessaloniki, Greece \\ e-mail: tsokalid@nured.auth.gr \\ E. Skourtou \\ University of the Aegean, Rhodos, Greece \\ e-mail: skourtou@rhodes.aegean.gr \\ (C) The Author(s) 2020
}

J. A. Panagiotopoulou et al. (eds.), Inclusion, Education and

Translanguaging, Inklusion und Bildung in Migrationsgesellschaften, https://doi.org/10.1007/978-3-658-28128-1_13 


\section{Introduction}

The contemporary world is challenged by demographic changes which make promoting diverse linguistic and cultural dexterity necessary not only for valuing all communities but also for the development of "skills, knowledges, and ways of being needed for success in the present and the future" (Paris and Alim 2017, p. 5). As Paris and Alim (2017) put it, the future is a multilingual and multiethnic one, regardless of attempts to suppress that reality (p. 6). This reality cannot but challenge educators to acknowledge and develop the diverse linguistic and cultural skills of their students as well as of themselves. To this end they call upon a Culturally Sustaining Pedagogy (CSP). This is in line with García's (2017) suggestion that teachers need to take up a "translanguaging stance", shed their authoritative position, and adopt different roles. She suggests that through TL teachers can take on the four roles of "detective", "co-learner", "builder" and "transformer". She notes that as teachers of migrants, they are also interested in social justice. Such an ideological stance requires them to become colearners of their students' worlds (through interviews, life stories, co-production of video-documentaries). At the same time, through translanguaging practices, teachers are also involved in transforming the social reality of their adult migrant/ refugee students, as they build on the human ability to re-mix and recontextualize; that is, to inscribe language performances and identities into new contexts (García 2017, p. 23). In this paper we will discuss aspects of translanguaging as a Culturally Sustaining Pedagogy (or CSP) (Paris and Alim 2017). We will then illustrate this connecting of the two concepts using data on views of bi/multilingual educators from a recent qualitative research (Tsokalidou 2017) that aimed to bring forward the issue of translanguaging (TL) in the everyday life of multi/ bilinguals from different parts of the world. In this paper, we will specifically present the perspectives of those bi/multilinguals who are involved in education. Our findings suggest that TL in education could function as a means of increasing the confidence and self-esteem of minoritized students, while offering them a feeling of normality and pride for their linguistic and cultural backgrounds.

\section{$2 \quad$ Translanguaging}

Translanguaging (Baker 2003, 2011; Garcia 2009a, b, 2011) could be considered one of the most dynamic contemporary sociolinguistic approaches to the study of linguistic variation (Tsiplakou 2016). Through this approach we look into what we refer to "beyond bilingualism" or beyond what has been called by Cummins 
(2007) the "two solitudes" or double monolingualism. Research in the area of bilingualism and language contact phenomena, within a fluid and ever-changing contemporary sociopolitical and educational context, has very little to benefit from a study in the types of bilingualism or in issues of maintaining heritage languages. Within the context of the constant need for (re)defining the deeper meaning and dimensions of language contact, of language itself, we attempt to muster all our intellectual tools in order to shed more light onto the issue of what we call "communicative collaboration", both on a personal and a collective level. Based on Tsokalidou (2017), we call "collaboration" the process whereby all our linguistic and cultural tools render us communicatively competent and in a position to handle our uniqueness as well as our explicit or implicit relations with the other members of the communities we inhabit as linguistically active and socially vibrant members. Translanguaging as a term, process and surrounding reality can express the collaborative relations that connect each person with his/her linguistic equipment, as well as with the rest of the members of the communicative communities in which s/he partakes (family, friends, professional context, etc.).

According to Tsiplakou (2016), it is common knowledge that most linguistic communities, synchronically and diachronically, are characterized by multilingualism and hybridity. In this context, she suggests that the approach of translanguaging puts forward a dynamic stance to language, not as a static system, but as languaging, a series of performances placed within specific social and cultural micro- and macro-contexts. Within the context of translingual performances, many elements from various linguistic repertoires can be put to use, producing a variety of multi-level sociocultural meanings and acts of identity. Thus, while translanguaging allows for values to be negotiated, and personal "voices" to be heard, it also creates a broader "platform" where issues of language ideologies and language policies can become more visible.

The term "translanguaging", or TL for short, was created by the Welsh educationalist Cen Williams in the 1980s in order to describe the planned and systematic use of two languages for teaching and learning within the same lesson (Baker 2003, 2011). It was coined as a Welsh word "trawsieithu" by Cen Williams and a colleague of his (Dafydd Whittall) during an in-service course for deputy headteachers in Llandudno (North Wales) and it was later translated into English as "translinguifying" but then changed to "translanguaging" following a conversation between Cen Williams and Colin Baker. "Translanguaging" came to mean the process whereby one language is used in order to reinforce the other with the aim to increase understanding and in order to augment the pupils' ability in both languages (Williams 2002, p. 40). In other words, through translanguaging, pupils internalize new ideas they hear, assign their own understanding to the 
message/concept and, simultaneously, utilize the message/concept in their other language(s), from their own perspectives. In doing so, they augment and supplement the message/concept through dual language processing. This idea seems to be in line with the notion of "transduction of meaning" (Kress 2000) and the "cone scheme" analysis developed by Skourtou (2011, p. 150), according to which shared content is expressed by similar concepts in each language, although the languages are different. Therefore, the cone scheme includes L1-L2 on top, $\mathrm{E} 1-\mathrm{E} 2$ in the middle and $\mathrm{C} 1=\mathrm{C} 2$ at the bottom, forming a cone. Although we find this idea very interesting, we believe that it expresses the approach to TL by Williams (2003), as the more recent approaches go beyond the dichotomy of L1 - L2, treating the language level in a similar manner to that of the concept and content levels, as we will discuss later.

Williams (2003) suggests that translanguaging focuses more on the pupils' use of two languages (and what they are able to achieve by using both languages) rather than on the teachers' role within the classroom, although it may be engineered by the teacher. Williams (2003) also suggested that through translanguaging often the stronger language is used in order to develop the weaker one thereby contributing towards a relatively balanced development of a child's two languages. This approach was important in the Welsh context as the aim was for the child to develop their two (or more) languages at school and translanguaging was seen as a strategy for retaining and developing bilingualism rather than one promoting the teaching of the second language. The four potential educational advantages of translanguaging put forward by Williams, as documented by Baker (2001, 2006, 2011) are:

a) the promotion of a deeper understanding of the subject matter

b) the development of the students' weaker languages

c) the facilitation of the co-operation between the home and the school and

d) the integration of fluent speakers with early learners.

Ofelia García (2009a, b) extended the term "translanguaging" to mean more than the pedagogic variation of linguistic input and output. García treats "translanguaging" as a strategy that bilinguals use to make meaning, shape their experiences, gain understanding and knowledge, and make sense of their bilingual worlds through the everyday use of two (or more) languages. García proposed the definition of "translanguaging" as "a powerful mechanism to construct understandings, to include others, and to mediate understandings across language groups" (García 2009a, p. 307 f.). García argues that it is impossible to live in communities such as New York and communicate among multilinguals without 
translanguaging (García 2009b, p. 151). Based on observations of translanguaging practices in bilingual communities, García's approach towards translanguaging helped extend the use of this process to include the complex everyday realities of home and street (García 2009a).

In other words, García (2009a, 2011) views translanguaging as "engaging in bilingual or multilingual discourse practices" (2009a, p. 44), as an approach centered not on languages, but on the communicative practices of bilinguals. Within the notion and process of translanguaging, other linguistic contact phenomena are included, such as code-switching and translation, but the emphasis is given on the process adopted by bilingual students in their classrooms, rather than on the languages involved.

The proposed approach to translanguaging seems to be in line with the approach to bilingualism proposed by Brutt-Griffler and Varghese (2004, p. 94), according to which "Bilinguals remind us that linguistic space is rather a continuum of Language (...) it is not only languages that cohabit in the same space but (...) also an accompanying process of (...) 'mixing of cultures and world views' that is impenetrable to some, troubling to others". In other words, according to the above approach, the fusion of different views and cultures plays a significant role in understanding bilingualism, and, at the same time, the traditional distinction of autonomous languages is abandoned as emphasis is given to the existence of a linguistic continuum as expressed by bilinguals themselves. This definition shows that the resistance to bilingualism is attributed, to a great extent, both to the concerns of the dominant society about a potential subversion of the linguistic norm, and to the failure of monolinguals to appreciate the importance of language coexistence for bilinguals and the rest of society (Tsokalidou 2015). Equivalent is the approach expressed by Velasco and García (2014), according to which the language practices learned by emergent bilinguals are in functional interrelationship with other language practices and form an integrated system. TL is more than code switching, which treats languages as separate systems (or codes) that are "switched" for communicative purposes. Moreover, we believe that while code-switching refers mainly to the language level, translanguaging allows us to refer to the wider ideological issues of multilingual management and the development of languages and language varieties, life in between different cultures and language varieties, elements which make up our personal and collective identity/identities. García and Kleyn (2016) make a thorough review of the literature on translanguaging, explaining the differences between TL approaches to code-switching and Cummins' interdependence hypothesis and emphasize that for them TL "refers to the deployment of a speaker's full linguistic repertoire, which does not in any way correspond to the socially and politically defined 
boundaries of named languages" (García and Kleyn 2016, p. 14). To express this, they refrain from using L1 or L2 and instead they symbolize language use as Fn and TL as a series of Fn (Fn, Fn, Fn, Fn...) where for code-switching and other traditional models of bilingualism the symbols L1 and L2 are used and Fn stands for any language use. They note that in the TL model, named languages such as English, Spanish and Russian have a material and social reality but not a linguistic one. They also explain that Williams' TL model refers to an internal linguistic view of language but it corresponds to an external social view of language, namely Welsh and English.

According to our approach, translanguaging could include a variety of adopted language practices such as translation, transference of elements, code-switching and others, while surpassing them at the same time. It becomes an educational and social practice that contributes to linguistic creativity through the synthesis of linguistic and cultural multimodal elements (Tsokalidou 2016). Through translanguaging we can, thus, overcome the socio-educational reality of "invisible" bilingualism, which refers to the existence but ignorance of the bilingual potential of students from various backgrounds in Greek schools, as these students are termed " $\alpha \lambda \lambda \hat{\sigma} \gamma \lambda \omega \sigma \sigma \alpha$ " ("alloglossa" meaning "other language speaking") and not bi/ multilingual, as their linguistic wealth remains simply invisible (Tsokalidou 2012, 2015, p. 44 f.).

\section{$3 \quad$ Culturally Sustaining Pedagogies (CSP)}

As Edwards (2004) proposes globalization has given multilingualism visibility but also an added value associated with the ability to speak several languages. However, not all language speakers receive the same added value for their languages (Tsokalidou 2017). Nonetheless, through translanguaging weaker or stigmatized languages can find a place along dominant ones whose value is not questioned. This is in line with the approach known as Culturally Sustaining Pedagogies (or CSP) (Paris and Alim 2017) which "calls for schooling to be a site for sustaining the cultural ways of being of communities of color" (p. 5). Like in the U.S, Greece and Europe as a whole are also challenged by demographic changes which make promoting diverse linguistic and cultural dexterity necessary not only for valuing all communities but also for the development of "skills, knowledges, and ways of being needed for success in the present and the future" (p. 5). As Paris and Alim (2017) put it, the future is a multilingual and multiethnic one, regardless of attempts to suppress that reality (p. 6). Paraphrasing the goals and content of Culturally Relevant Pedagogy (CRP) (Ladson-Billings 2017), translanguaging can 
become a powerful means of expressing the ways in which race, ethnicity, language, literacy and engagement with culture are enacted in shifting and dynamic ways. The coexistence of languages, the constant references to the need for more than one, imposed upon us, way of being and expressing oneself, the need to sustain elements from our familial and communal lives along with elements that connect us to our contemporaries, while leading us to a common diverse and dynamic future can be located and expressed through creative translanguaging practices. As participants mentioned when asked to expand on the notion of translanguaging, cultures and languages need to be sustained as fluid, ever-changing and dynamic, according to the many and complex ways in which people place themselves within and beyond ethnic, cultural and linguistic groupings in their effort to define their own sociolinguistic universe.

According to its founders (Paris and Alim 2017), CSP relies on the theories of funds of knowledge, the third space and culturally relevant pedagogy. Funds of knowledge refer to the knowledge that students bring with them from their homes and communities and which needs to be used for their cognitive and overall development (González et al. 2005). Third Space theory focuses on the uniqueness of each person as a hybrid (Gutierrez 2008) and is used in order to understand and bring forward the spaces "in between" two or more discourses or binaries (Bhabha 1994). Through this approach we can appreciate the process whereby people negotiate and synthesize their traditional cultural background with newly imposed cultures, creating their unique third space cultures. Culturally Relevant Pedagogy (CRP) involves three main components which are:

a) a focus on student learning,

b) developing students' cultural competence and

c) supporting their critical consciousness (Ladson-Billings 2017).

Ladson-Billings (2017) discusses how these three components have been misunderstood and misused by teachers who seem to follow culturally relevant pedagogy. She stresses, among other issues, the fact that culture goes far beyond issues or lists of "cultural tendencies" or "cultural stereotypes", encompassing worldview, thought patterns, ethics, epistemological stances and ways of being that are fluid and dynamic (p. 143). Through a study of both CRP and CSR, it becomes evident that such approaches cannot be implemented without involving multilingual and translingual practices in class. As it has been shown from our research, language and culture are so intertwined that they cannot be separated in our efforts to sustain them as we support our multilingual/multicultural students within and outside the classroom context. The work of Bucholtz et al. (2017) 
makes this connection evident, too, as they claim that one "of the most important yet most devalued resources available to youth of color is their language", which is often and superficially described as "improper", "sloppy", "ungrammatical" or "broken" rather than as innovative, creative or flexible, central to young people's creation of their identities (p. 44). As the same writers claim, the recognition of the importance of language in the lives of youth of color has led Paris and Alim (2017) to include "the valorization of language as a central component of CSP" (p. 44). The impossibility of separating language from culture is made clear in the statement by Bucholtz et al. (2017) that "it is culture, produced primarily via language, that endows experience with meaning and provides a deeply held sense of identity and social belonging" (p. 45). Although the work of Bucholtz et al. (2017) refers mainly to youth of color, we believe that the same premise holds for all minoritized students in general as well as adults who often feel that their color or their ethnic/cultural/linguistic backgrounds place them in a position of feeling like a "wog" or a "gharib" (Tsokalidou 2017). This feeling is not just a personal matter, but it reflects vividly the established structural power inequalities between mainstream and minorized communities in migration communities. In this context it is worth highlighting the point made by Paris and Alim (2017) that "too often cultural practices, activities, and ways of being and doing are invoked in ways that obscure the racialized, gendered, classed, dis/abilitied, language (and so on) bodies of the people enacting them." (p. 9). Just like culture and language cannot be sustained separately, Paris and Alim claim that CSP is about sustaining cultures in relation to sustaining the bodies and the lives "of people who cherish and practice them" (p. 9). This is an important aspect that makes cultural values and realities person-specific and person-centred and helps educators and students realize the individual complexities and idiosyncrasies that matter for people within the contexts of their ethnic and other affiliations. Such a realization makes the bond between CSP and translanguaging even more vital as we all need to appreciate the unique ways in which individuals and groups express their universe combining all the linguistic (which are also culturally sustaining) means available to them.

In their discussion of multilingualism, Cenoz and Corter (2015) note that during the last 15 years there has been a shift from a cognitive to a social perspective in the fields of second language acquisition and bilingualism, as well as a turn towards multilingualism. Within this context the distinction between a second and a foreign language seems to lose its momentum. The example of the sociolinguistic context of countries in regions other than Europe, such as Lebanon and other countries in the Middle East, has given us more parameters to consider (Tsokalidou 2000, 2012) which challenge traditional terms used in language learning 
and use. Having studied the written work of immigrant students in Greece, Archakis (2019) notes that the issue of hybridity and hybrid identities, as it surfaces from the students' own texts, needs to be taken into consideration in the planning of language teaching. Archakis proposes that the terms "teaching Greek as a second or foreign language" within the context of hybridity and diversity are at least redundant, while a more general term such as "language teaching" can be more accurate and meaningful. Equivalent issues of the inadequacy of monolingual language tests for adult immigrants in Greece have been noted by other researchers (Androulakis 2015; Moschonas 2010). This approach seems to be in line with the holistic view of the linguistic repertoire as adopted in "Focus on Multilingualism", a research and teaching approach for multilingual contexts (Cenic and Seltzer 2011). This approach encourages students to use their resources cross-linguistically rather than separately (Cenoz and Gorter 2015). Blommaert (2010) proposed the term "truncated multilingualism" in order to describe the use of bits and pieces from different languages that people have at their disposal while communicating in multilingual contexts as "repertoires composed of specialized but partially and unevenly developed resources" (p. 23). Although we find the term appropriate for many multilingual communicative contexts, we prefer to describe this process as translanguaging, as the term "truncated" might have negative connotations that may not do justice to the often miraculous way in which people actually manage to communicate across individual or named, according to García (2016), language borders. We can say that despite the limitations set by one's lack of knowledge of many aspects of the languages that make up one's "linguistic universe", communication does happen and strong bonds do form between people from diverse backgrounds.

\section{The Research: Methodological Issues, Research Sample and Findings}

The research presented here belongs to a qualitative research paradigm and the analysis carried out can be described as qualitative content analysis (Tsokalidou 2017). As Zhang and Wildemuth (2009) suggest, "qualitative content analysis goes beyond merely counting words or extracting objective content from texts to examine meanings, themes and patterns that may be manifest or latent in a particular text. It allows researchers to understand social reality in a subjective but scientific manner" (p. 1). Qualitative research is fundamentally interpretative, and interpretation represents our personal and theoretical understanding of the phenomenon under study (Patton 2002). However, the current research can be 
characterized as inductive within a grounded theory approach, according to which the researcher does not derive variables/categories from existing theories or previous related studies but immerses herself in the data and lets the categories emerge on their own.

The data presented below is part of the research by Tsokalidou (2017) which involved a broader range of issues to be addressed. In this paper we focus on the data regarding bi/multilingual educators and their views on TL practices. The data were gathered through a combination of oral communication and interviews with the participants. Since they all live in different countries (Australia, Sri Lanka, Dubai, Germany, Italy, Thailand and Greece) the interview questions were, in some cases, sent to them by email and communication with them took place either through social media or in person. In every case, however, the participants themselves wrote or corrected the content of the provided answers and had control over the way in which they answered the questions. The purpose of the research and its focal concept of translanguaging were explained to them, while a short definition of TL was provided in the written interview questions. The bilingual participants were encouraged to express their views on the given topics. They all wanted their own name to be used in the analysis as they all expressed their desire for their voice to be heard.

The findings presented come from the following bi/multilingual participants who are all involved in education. Valbona, 45, is an Albanian background woman living in Greece who teaches Albanian to Albanian-background students. She regards Albanian, Greek and English as her languages of use. Stacey, 26, is a Greek-background woman living in Canada who teaches Greek to Greek-background students. She mentioned English, Greek, French, Italian, (some) Arabic, (some) Hebrew and (some) Turkish as her languages of use. Devika, 50, is an Australian-Sri Lankan woman living in Sri Lanka who teaches English to tertiary education students. She mentioned English, French, Italian, Spanish, Korean and Sinhala as her languages of use. Gianna, 55, is a Greekbackground woman living in France, teaching French to students in informal French education. She referred to Greek, French, Russian and English as her languages of use. Kathy, 39, is a bilingual (American-)Lebanese-background woman living in Dubai, carrying out seminars on self-improvement to adults. She uses English, Arabic, French and Spanish. Max, 68, is a Greek-background man living in Adelaide, Australia, teaching theater to students in formal education. $\mathrm{He}$ mentioned Greek, English and French as his languages of use. Last but not least, Badal, 57, is a man from Pakistan who lives in Italy and teaches ethnology to University students. He uses Balochi, English, Urdu and Italian to communicate. 


\section{$5 \quad$ Educators' Perspectives on Translanguaging}

The participants answered questions about the use of TL in class, the possible advantages and disadvantages of TL for both bi/multilingual and monolingual students. Below we examine their main responses.

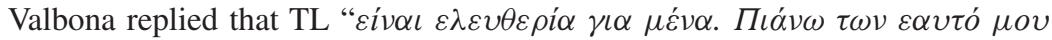

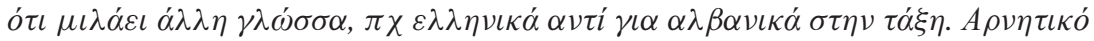

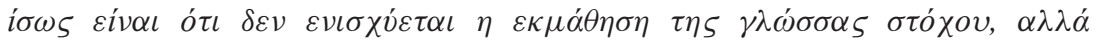

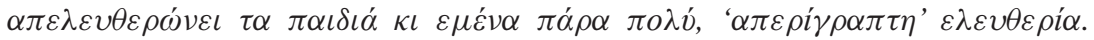

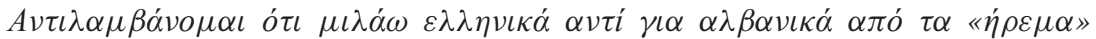

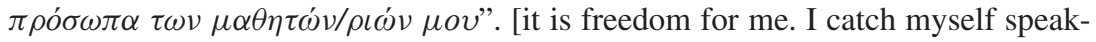
ing another language, i.e. Greek instead of Albanian in class. Perhaps it is negative as the learning of the target language is not reinforced but it frees the children and me very much, "indescribable" freedom. I realize that I speak Greek instead of Albanian when I see the "calm" faces of my students].

Stacey said "I question the absolute immersion (in my case the immersion into the Greek language) and use of the languages my students speak. In addition, I am certain that the use of multiple languages will boost their confidence and self-esteem. I also turn to code switching when I teach, in order to ease the language-learning process. Especially now that I teach to English-speaking preschoolers Greek I need to switch between English and Greek often, otherwise they don't understand and lose interest". Moreover, she commented that "By allowing students to speak in their own language and by enabling them to share their heritage language with their classmates, we raise their self-respect and shape a positive environment for them. Furthermore, TL eases the educational process. It makes it quicker and easier for students to understand a new concept or idea, as they will relate it to previous knowledge".

Especially in relation to the monolingual students, Stacey said that "This cultural and linguistic exposure fosters an unprejudiced attitude for monolingual students and promotes a peace building and conflict resolution culture".

When asked about her own language use in class, Devika replied that "I am currently learning to understand Sinhalese, and expanding my vocabulary and phraseology, to enable me to create course materials in English for students from rural and regional areas who are cut off from the wider world. There is a need for me to start to think as they do, to understand how best to reach them and help them equip themselves with English skills in a way which respects their original language and cultural base". Moreover, according to Devika, translanguaging lessens her "perceived remoteness" from her students, while it "opens our minds 
to think outside our own exclusive frame of reference. It helps us stay open and fluid and adaptive, in dealing with others".

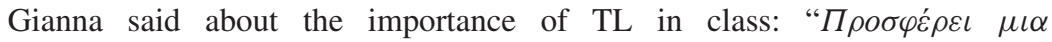

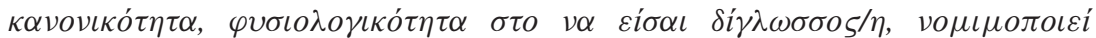

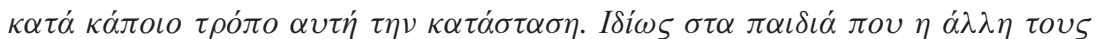

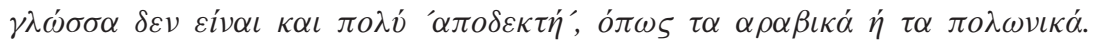

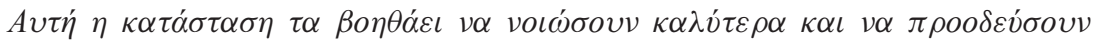

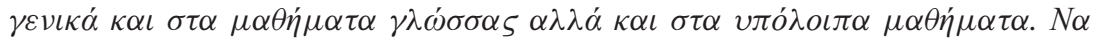

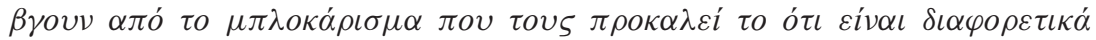

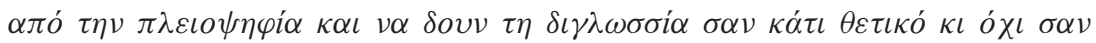
$\varepsilon \lambda \alpha ́ \tau \tau \omega \mu \alpha$ " [It offers a sense of normality to being a bilingual, it legitimizes, somehow, this situation. Especially for children whose other language is not very "acceptable", like Arabic or Polish. This situation helps them feel better and make general progress in language class as well as in the other classes. To get out of the blockage caused by the fact that they are different from the majority and to see their bilingualism as something positive and not a defect].

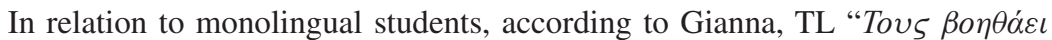

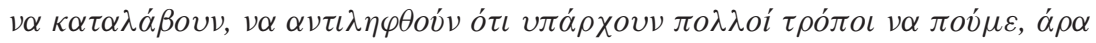

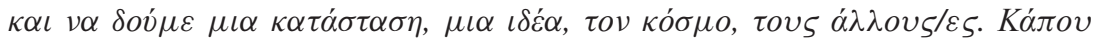

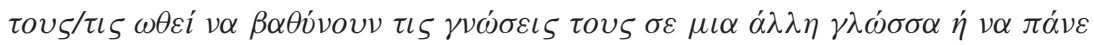
$\kappa \alpha \iota \sigma \varepsilon \mu \iota \alpha \dot{\alpha} \lambda \lambda \eta \gamma \lambda \omega \dot{\sigma} \sigma \sigma \alpha, v \alpha \mu \eta \mu \varepsilon i v o v v \mu o v o ́ \gamma \lambda \omega \sigma \sigma o \iota / \varepsilon \varsigma$ " [helps them understand, realize that there are many ways to express, to see a situation, an idea, the world, the others. Somehow it urges them to deepen their knowledge in another language or to go to another language, not to remain monolingual].

Kathy said about TL: "I think it's something that good teachers do anyway. In my classes I'll use slang, Arabic or French words to get my meaning across if I feel it resonates more with my students. I'm also careful to pick up their language and re-use it to explain things rather than sticking to textbook terminology". When asked about monolingual and bilingual students in her classes, she comments that "Most of my students are bi-and tri-lingual. I don't have any monolingual students, what I have is mono-cultural or mono-socialized students and that makes for a greater barrier to teaching new concepts than language does I think". When students are narrowly socialized and educated they have a harder time being flexible and accepting of new ideas. Remember that I teach innovation and entrepreneurship so the students that have traveled more, explored more and experienced more are much faster at picking up and adopting new concepts that the ones that have stayed put. 
Max said the following: "Well, clearly, students can feel 'more comfortable' about crossing bridges in communications. Sometimes, language classes are quite strict and the teacher demands that responses must only be in the language under study. I know from personal experience this puts great pressure on individuals who may avoid the task to avoid embarrassment".

'If you provide this "freedom of speech' you will have many more "teachable moments" in your classes".

Badal said about TL in class: "My personal opinion is that such a process might be very effective for students from all backgrounds. It increases the confidence of those kids who are a minority in number and whose language is not the medium of instruction or communication in school and society but also to the host students who, learning a few words from the minority/guest language, create a kind of bridge to approach the world of the minority'...'each language has its place in this mosaic of the world of diversities but also of similarities at the same time".

From the participants' own views, we can see that, according to bi/multilinguals involved in education, TL provides as a means of increasing confidence and self-esteem for minority/minoritized students, gives them "indescribable freedom" (in the words of Valbona above), "strength of thought", a feeling of pride, a deeper adaptability and openness and as Max mentions this freedom of speech provides "more teachable moments". This last point about creating more teachable moments seems to be in line with the argument put forward by García and Kleyn (2016) that translanguaging in education is not random or haphazard but strategic. Although the insights of the participants in this research project focus on broader cultural rather than linguistic goals in their TL teaching practices, the opportunities created through them have strategic importance for the class context. As Gianna and Badal suggest, assisting the students' need to overcome any negative feelings attached to the other, minoritized, languages and cultures and giving them a sense of normality and belonging is one major strategic goal in education and TL can be a very powerful means of achieving it. Moreover, the participants' views on TL in education seem to be in line with the research findings of University students who were asked to participate in multilingual practices (Kyppö et al. 2015), such as the importance of cultural contexts and their impact on language use and TL especially. As Kathy suggested, in order for the benefits of multi/bilingualism to become evident, it is important that cultural aspects are developed, since mono-culturalism may hinder human development more so than monolingualism. The use of various languages allows for other "voices" to be heard and have a place within social and educational norms. 


\section{Conclusions}

Within an educational context, the strategic use of TL, as explored by García and Kleyn (2016), could be aligned with the idea of creating more teachable moments. This is suggested by our findings as well. Other main issues that surfaced from our research are TL as a means of assisting students to overcome any negative feelings attached to their other languages and cultures and giving them a sense of normality and belonging, which is another major strategic goal in education for social justice. Moreover, TL in education is related to the importance of cultural contexts and their impact on language use (also suggested by Kyppö et al. 2015), the restriction of monocultural perspectives and the treatment of bilingualism as the embodiment of the world's cultural diversity.

TL for our participants appeared to be a powerful means of cultivating a deeper understanding of the world, offering openness, adaptability and creating more teachable moments. However, it also became clear from the bi/multilingual educators' perspectives that going against the grain of monolingualism and monoculturalism within and beyond the educational context is a great challenge for all, even for those who strongly believe that it is only through TL that all "voices" can be heard and given a place within social and educational norms.

However, all agree that it is important to highlight diverse cases where students are given the space to perform using their full linguistic repertoire, and educators are multifunctionally designing and incorporating TL spaces into their teaching and the everyday life of their classrooms (Fu et al. 2019). This way we could follow how educators develop their TL stance, how students are practicing it, and how TL itself results to benefits both on emotional and cognitive aspects of learning and schooling of these students. As García concludes in her foreword to Fu et al. (2019): "It is all here "within reach"”.

\section{References}

Androulakis, G. (2015). Me proshima tin adikimenikotita: Provlimata sti hrisi ton test gloomathias os kritiriu gia tin politografisi ton metanaston/-rion ke I apetisi gia kinonioglosologiki erevna [Objectivity is the pretext: problems in the use of language tests as a criterion for naturalization of migrants and the demand for sociolinguistic research] [in Greek]. In Androulakis, G. (Ed.), Glosiki pedia: 35 meletes afieromenes ston kathigiti Napoleonda Mitsi (pp. 287-302). [Language education: 35 studies dedicated to professor Napoleon Mitsis] [in Greek]. Athens: Gutenberg.

Archakis, A. (2019). I didaskalia tis elinikis os defteris/xenis glosas ipoi to prisma tu ethniku ke meta-ethniku logu: protasis glosikis politikis. [the teaching of Greek as a 
second/foreign language from the point of view of national and post-national discourse: suggestions for language policy] [in Greek]. In: Skourtou, E., Kourti-Kazoullis, V., Aravositas, Th \& Trifonas, P. (Eds.) Zitimata Glosas, Eterotitas ke Ekpedefsis (pp. 49-57). [Issues of language, otherness and education] [in Greek]. Athens: Gutenberg.

Baker, C. (2001). Foundations of bilingual education and bilingualism (3rd edition) Clevedon: Multilingual Matters.

Baker, C. (2003). Biliteracy and transliteracy in Wales: Language planning and the Welsh National Curriculum. In N.H. Hornberger (Ed.), Continua of biliteracy: An ecological framework for educational policy, research and practice in multilingual settings (pp. 71-90). Clevedon: Multilingual Matters.

Baker, C. (2006). Foundations of bilingual education and bilingualism (4th edition). Clevedon: Multilingual Matters.

Baker, C. (2011). Foundations of bilingual education and bilingualism (5th edition). Clevedon: Multilingual Matters.

Bhabha, H. (1994). The location of culture. London: Routledge.

Brutt-Griffler, J. \& Varghese M. (2004). Introduction. Special Issue: (Re)writing bilingualism and the bilingual educator's knowledge base. International Journal of Bilingual Education and Bilingualism 7(2) \& 7(3), 93-101.

Blommaert, J. (2010). The Sociolinguistics of Globalization. Cambridge: Cambridge University Press.

Bucholtz, M., Casillas, D. I., \& Lee, J. S. (2017). Language and Culture as Sustenance. In Paris, D. \& Alim, H.S. (Eds.) Culturally Sustaining Pedagogies. Teaching and Learning for Justice in a Changing World (pp. 43-59). Columbia University: Teachers College.

Cenic, C. \& Seltzer, K. (2011). Translanguaging: A CUNY-NYSIEB Guide for Educators. New York: The City University of New York, The Graduate Center, CUNY-NYSIEB.

Cenoz, J. \& Gorter, D. (Eds.) (2015). Multilingual Education. Between language learning and translanguaging. Cambridge: Cambridge University Press.

Cummins, J. (2007). Rethinking monolingual instructional strategies in multilingual classrooms. The Canadian Journal of Applied Linguistics 10, 221-240.

Edwards, J. (2004). Foundations of Bilingualism. In Bhatia, T.K. \& Ritchie, W.C. (Eds). The Handbook of Bilingualism (pp. 7-31). Hoboken: Wiley-Blackwell.

Fu, D., Hadjioannou, X., Zhou, X. (2019). Translanguaging for Emergent Bilinguals -Inclusive teaching in the Linguistically Diverse Classroom. New York: Teachers College Press.

García, O. (2009a). Bilingual education in the 21st century: a global perspective. Oxford: Wiley-Blackwell.

García, O. (2009b). Education, multilingualism and translanguaging in the 21st century. In: A.K. Mohanty, M. Panda, R. Phillipson and T. Skutnabb-Kangas (Eds.) Multilingual education for social justice: globalising the local (pp. 128-145). New Delhi: Orient Black Swan.

García, O. (2011). Educating New York's bilingual children; constructing a future from the past. International Journal of Bilingual Education and Bilingualism 14, 133-153.

García, O. (2016). Living and studying polyd(r)omously: A self reflection. Polydromo 9, (7-10). 
García, O. (2017). Problematizing linguistic integration of migrants: the role of translanguaging and language teachers. In: Beacco, J.C., Krumm, H-J, Little, D., Thalgott, P. (Eds.) The Linguistic Integration of Adult Migrants/L'intégration linguistique des migrants adultes. Some lessons from research/Les enseignements de la recherché (pp. 11-26). Council of Europe: De Gruyter Mouton.

García, O. \& Kleyn, T. (Eds.) (2016). Translanguaging with multilingual students. Learning from Classroom Moments. New York: Routledge.

González, N., Moll, L., \& Amanti, C. (Eds.). (2005). Funds of knowledge: Theorizing practices in households, communities and classrooms. New Jersey: Erlbaum.

Gutierrez, K. (2008). Developing a sociocritical literacy in the Third Space. Reading Research Quarterly 43, 148-164.

Kress, G. (2000). Multimodality: Challenges to Thinking About Language. TESOL Quarterly 34 (2), 337-340.

Kyppö, A., Natri, T., Pietarinen, M., \& Saaristo, P. (2015). Use your languages! From monolingual to multilingual interaction in a language class. In J. Jalkanen, E. Jokinen, \& P. Taalas (Eds.), Voices of pedagogical development - Expanding, enhancing and exploring higher education language learning (pp.319-335). Dublin: Research-publishing.net. https://doi.org/10.14705/rpnet.2015.000297.

Ladson-Billings, G. (2017). The (R)Evolution Will Not Be Standardized. Teacher Education, Hip Hop Pedagogy, and Culturally Relevant Pedagogy 2.0. In Paris, D. \& Alim, H.S. (Eds.), Culturally Sustaining Pedagogies. Teaching and Learning for Justice in a Changing World (pp. 141-156). New York: Teachers College Press.

Moschonas, S. A. (2010). Exoristi sti glosa: Glosikos apoklismos ke I kratiki pistopiisi tis glosomathias. [Exiled in the language: Language exclusion and the state certification of language learning] [in Greek] Elelef, 54-58.

Paris, D. \& Alim, H.S. (Eds.) (2017). Culturally Sustaining Pedagogies. Teaching and Learning for Justice in a Changing World. New York: Teachers College Press.

Patton, M.Q. (2002). Qualitative Research and Evaluation Methods. Thousand Oaks. CA: Sage.

Skourtou, E. (2011). I diglosia sto sholio. [Bilingualism at school] [in Greek]. Athens: Gutenberg.

Tsiplakou, S. (2016). 'Akindini' enalagi kodikon ke diaglosikotita. It's complicated. ['Harmless' code-switching and translanguaging. It's complicated] [in Greek]. Epistimes Agogis, 140-160.

Tsokalidou, R. (2000). Hartografontas tin Elinofoni Pragmatikotita: Livanos \& Syria [Mapping the Greek-speaking reality: Lebanon \& Syria]. Digital publication, Centre for the Greek Language. http://www.komvos.edu.gr/syria/index.htm

Tsokalidou, R. (2012). Horos gia dio: Themata diglosias ke ekpedefsis. [Space for two:

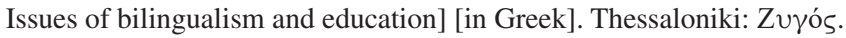

Tsokalidou, R. (2015). Bilingualism otherwise: Research approaches towards language contact issues and the inclusion of bilingual children in the Greek school. In Tressou, E., Mitakidou, S. \& Karagianni, P. (Eds.). Roma inclusion-International and Greek Experiences. Complexities of inclusion (pp. 164-177). Thessaloniki: Copy City. 
Tsokalidou, R. (2016). Beyond language borders to translanguanging within and outside the educational context. In Carroll E. Wilson (Ed.) Bilingualism: Cultural Influences, Global Perspectives and Advantages/Disadvantages (p. 108-118). New York: Nova Science Publishers.

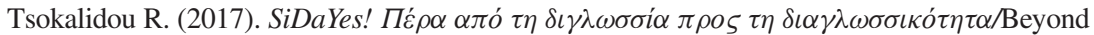
bilingualism to translanguaging. Athens: Gutenberg.

Velasco, P. \& García, O. (2014). Translanguanging and the writing of Bilingual Learnes. The Journal of the National Association for Bilingual Education 37:1, 6-23.

Williams, C. (2002). A Language gained: A study of language immersion at 11-16 years of age. Bangor: School of Education. https://www.bangor.ac.uk/addysg/publications/Language_Gained\%20.pdf.

Williams, C. (2003). Defnyddio trawsieithu i ddatblygu llythrennedd deuol. In: G. Roberts and C. Williams (Eds.), Addysg Gymraeg - Addysg Gymreig (pp. 288-312). Bangor: School of Education.

Zhang, Y. \& Wildemuth, M. B. (2009). Qualitative Analysis of Content. Analysis 1 (2), $1-12$.

Open Access This chapter is licensed under the terms of the Creative Commons Attribution 4.0 International License (http://creativecommons.org/licenses/by/4.0/), which permits use, sharing, adaptation, distribution and reproduction in any medium or format, as long as you give appropriate credit to the original author(s) and the source, provide a link to the Creative Commons license and indicate if changes were made.

The images or other third party material in this chapter are included in the chapter's Creative Commons license, unless indicated otherwise in a credit line to the material. If material is not included in the chapter's Creative Commons license and your intended use is not permitted by statutory regulation or exceeds the permitted use, you will need to obtain permission directly from the copyright holder.

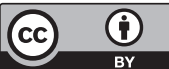

